\title{
Heroin Dependency Treatment: A New Approach
}

\section{Jamshid Ahmadi}

Substance Abuse Research Center, Shiraz University of Medical Sciences, Shiraz, Iran

*Corresponding author: Jamshid Ahmadi, MD, Professor of Psychiatry, Founder and Director, Substance Abuse Research Center, Shiraz University of Medical Sciences, Shiraz, Iran, E-mail: Jamshid_Ahmadi@yahoo.com

\begin{abstract}
Background: Heroin dependency is a globally problem.

Objective: To explain the efficacy of low dose of clonidine, tizanidine and ibuprofen (NSAID) in the treatment of heroin dependency.

Method: To evaluate a single case

Results: Combination of clonidine $0.4 \mathrm{mg}$, tizanidine $8 \mathrm{mg}$ and ibuprofen $800 \mathrm{mg}$ per day is very effective in the management of heroin withdrawal symptoms and craving. Discussion: Our findings indicate that low dose of clonidine, tizanidine and ibuprofen (NSAID) is beneficial in the treatment of heroin dependency. This is a positive result. Conclusion: To the author's knowledge positive effects of combination of clonidine, tizanidine and ibuprofen in these situations have not been published yet, and this finding is an important addition to the literature.
\end{abstract}

Keywords: Heroin; Withdrawal; Clonidine; Tizanidine; NSAID
Received Date: November 4, 2015

Accepted Date: November 30, 2015

Published Date: December 5, 2015

Citation: Ahmadi, J. Heroin Dependency Treatment: A New Approach. J Addict Depend 1(2): 32- 34.

DOI: $10.15436 / 2471-061 X-15.010$

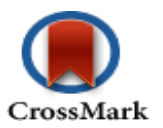

\section{Introduction}

Heroin is a derivative of morphine that was originally introduced as a non addictive derivative of morphine. Heroin is an opioid mu receptor agonist ${ }^{[1]}$. Opium has been used for many centuries and has a long history of medical and social acceptance in some parts of the world, not only in the opium-producing countries of Asia such as Afghanistan, but also during the $19^{\text {th }}$ and very early $20^{\text {th }}$ centuries, in North America and Europe $e^{[2,3]}$.

Mental disorders are globally growing ${ }^{[4-23]}$. In psychiatric disorders, substance related disorders, especially opioids and stimulants induced disorders have been considered as progressive worldwide problems. Nowadays, stimulants abuse and stimulants-induced psychiatric disturbances are a growing problem has produced more presentations to outpatient clinics, emergency departments, and inpatient psychiatric units ${ }^{[24-67]}$. The FDA (Food and Drug Administration) approved use of clonidine for the treatment of hypertension, tizanidine for the treatment of spasticity, and nonsteroidal anti-inflammatory drugs (NSAIDS) for the reduction of pain, inflammation, and fever ${ }^{[1]}$.

At the present case report we are using combination of tizanidine, clonidine and ibuprofen (NSAID) as a new approach for the treatment of severe heroin withdrawal symptoms and craving. We ourselves prepared a reliable and valid scale ${ }^{[24-26]}$ to evaluate the withdrawal craving based on DSM-5 criteria for heroin craving, ranging from 0 to 10 (0 means no craving at all and 10 means severe craving and temptation all the time).

Craving scale: $0-1-2-3-4-5-6-7-8-9-10$.

To the authors' understanding and knowledge we could not find enough controlled published trials on this matter?

So, study of this case could represent a new finding.

\section{Case Presentation}

We describe a patient with heroin dependency who dramatically responded to combination of clonidine, tizanidine and ibuprofen (NSAID).

Copyrights: (C) 2015 Ahmadi, J. This is an Open access article distributed under the terms of Creative Commons Attribution 4.0 International License. 
AZ was a single, 18 year old barber with grade 3 of middle school education. He lived with his parents in Shiraz city of Fars province in south of Iran. AZ began frequent use of opium and tramadol at age of 13. After several months he began smoking of marijuana and methamphetamine (Meth) as well. Since one month Prior to Admission (PTA) he began smoking heroin.

Because of agitation and depression, he was admitted in psychiatric emergency room. Urine drug screening tests were positive for morphine, methadone, cannabis and benzodiazepine. During admission he received olanzapine $10 \mathrm{mg}$, sodium valproate $600 \mathrm{mg}$ and chlorpromazine $50 \mathrm{mg}$ per day for the treatment of depression and insomnia. After 3 days he was transferred to Dual Diagnosis Ward. In psychiatric interview and examinations he was depressed, restless and agitated. In exact physical and neurological examinations we could not find any abnormal findings. Serology for viral markers (HIV, HCV and $\mathrm{HB} \mathrm{Ag}$ ) was normal.

According to DSM- 5 criteria, and also complete medical, psychiatric, and substance use history AZ was diagnosed as "opioid (heroin) dependent and opioid induced mood disorder" AZ received clonidine $0.4 \mathrm{mg}$, tizanidine $8 \mathrm{mg}$ and ibuprofen $800 \mathrm{mg}$ per day for the treatment of heroin withdrawals. He reported symptoms of opioid withdrawal especially pain and craving when he was admitted in emergency room. The mean scores of heroin craving for 4 days of admission in emergency room was 6 out of 10 and for 7 days of Dual Diagnosis Ward (after taking clonidine, tizanidine and ibuprofen) was 1.5.

Based on the interview and closely monitoring ( 3 times a day) for heroin, he experienced much more heroin withdrawal craving before taking medications (Mean: 6) than after taking medication (Mean: 1.5). One day before leaving hospital, urine drug screening tests were negative for morphine, methadone cannabis and benzodiazepine. He was improved and discharged without any heroin withdrawal symptoms after 7 days of admission in Dual Diagnosis Ward. Patient was especially monitored and interviewed (by a nurse who did not know the patient's medications) only for heroin withdrawals and craving, 3 times a day (morning, afternoon, evening).

$\mathrm{AZ}$ was taking medications and his condition was improving every day.

Based on the interview and closely monitoring ( 3 times a day), he experienced much more heroin withdrawals and craving before taking medication than after taking medication.

\section{Discussion}

It should be emphasized that clonidine is an alpha 2 receptor agonist and a sympatholytic drug, so decreases heroin withdrawal symptoms such as lacrimation, rhino rhea, diarrhea, abdominal cramp and hypertension. Tizanidine decreases muscle spasm induced by withdrawal of heroin. Ibuprofen decreases heroin withdrawal pain ${ }^{[1,24]}$. Our study elucidates that clonidine 0.4 , tizanidine $8 \mathrm{mg}$ and ibuprofen $800 \mathrm{mg}$ per day is very useful in the reduction and cessation of heroin withdrawal and craving. Therefore this case study is an important addition to the literature.

\section{Conclusions}

Low doses of tizanidine, clonidine, and ibuprofen are very effective in the management of opioids withdrawal symptoms. This is a significant finding.

Acknowledgement: We were financially on our own.

\section{Conflict of interests: None to be declared.}

\section{References}

1. Sadock, B., Sadock, V., Ruiz. P. (Editors) Kaplan \& Sadock'S Synopsis of Psychiatry: (2015) Lippinott Wiliams and Wilkins, Philadelphia (USA).

2. Brian, J. Opium and infant-sedation in 19th century England, (1994) Health Visitor 67(5): 165-166.

3. Jonnes, J. The rise of the modern addict. (1995) Am J public Health 85(8): 1157-1162.

4 MackaySmith, M., Ahmadi, J., Pridmore, S. Suicide In Shooting Galleries. (2015) ASEAN Journal of Psychiatry. 16(1): January - June: XX-XX.

5. Mani, A., Dastgheib, S.A., Chanoor, A., et al. Sleep Quality among Patients with Mild Traumatic Brain Injury: A Cross Sectional Study. (2015) Bull Emerg Trauma 3(3): 9396.

6. Ahmadi, J., Alshawa, H., Ahmed, M.G., et al. Mental Health of Dubai Medical College Students. (2012) Iran J Psychiatry Behave Sci 6(2): 7983.

7. Pridmore, S., Ahmadi, J., Reddy, A. Suicide in the absence of mental disorder. (2012) Working paper of public health 6: 113.

8. Pridmore, S., Brüne, M., Ahmadi, J., et al. Echopraxia in schizophrenia: possible mechanisms. (2008) Aust N Z J Psychiatry 42(7): 565571. 9. Pridmore, S., Robinson, J., Ahmadi, J. Suicide for scrutinizers. (2007) Australas Psychiatry 15(3): 247248.

10. Ahmadi, J., Samavatt, F., Sayyad, M., et al. Various types of exercise and scores on the Beck Depression Inventory. (2002) Psychol Rep 90(3): 821822.

11. Pridmore, S., Ahmdi, J., Majeed, Z.A. Suicide in Old Norse and Finnish folk stories. (2011) Australas Psychiatry 19(4): 322324.

12. Pridmore, S., Ahmdi, J. Two cases of 'Type 3' suicide. (2010) Australas Psychiatry 18(5): 426430.

13. Pridmore, S., Ahmadi, J. Usage of download of psychiatry by Muslim countries. (2011) Bulletin of clinical psychopharmacology 21(2): 174.

14. Ahmadi, J., Ahmadi, N., Soltani, F., et al. Gender differences in depression scores of Iranian and German medical students. (2014) Iran J Psychiatry Behav Sci 8(4): 7073.

15. Ahmadi, J., Toobaee, S., Alishahi, M. Depression in nursing students. (2004) J Clin Nurs 13(1): 124

16. Ahmadi, J., Pridmor, S., Fallahzadeh, M. Neurotic scores in a Sample of medical students. (2004) German J Psychiatry 7: 5155.

17. Ahmadi, J. Human and Pain. (1993) J Health Society 3(13).

18. Ahmadi, J. Behavior therapy and Biobehavior therapy a comparative view. Vol.8. No 1 and 2, fall and Spring (19921993) J Social Sci Human of Shiraz University.

19. Ahmadi, J. A view on Biobehavior therapy. Vol.2, (1992) J Pulse "Specific for Refreshment of Medical Community.

20. Ahmadi, J. The Future of Psychiatry (A novel theory and a new approach), Shiraz, Rahgosha Press, Second edition, (1992) Shiraz Univ Med Sci.

21. Ahmadi, J. Behavior Therapy, Shiraz, (1991) Shiraz Univ Press Third edition.

22. Ahmadi, J. Emotion, Feeling and NonVerbal Communication, Shiraz, Rahgosha Press, (1990) Shiraz Univ Med Sci.

23. Ahmadi, J. Obsessive Compulsive Disorder, Shiraz, Navid Press, Second edition, (1989) Shiraz Univer Med Sci.

24. Ahmadi, J. Tramadol Dependency Treatment: A New Approach. (2015) J Addict Med Ther Sci 2(1): 001-03.

25. Ahmadi J. The Effect of Buprenorphine and Bupropion in the Treat- 
ment of Methamphetamine Dependency and Craving. (2015) Br J Med \& Med Res 10(2): 14.

26. Ahmadi, J., Sahraian, A., Dastgheib, S.A., et al. Management of Methamphetamine Induced Psychosis by 8 sessions of ECT. (2015) Sch J App Med Sci 3(3H): 15651566.

27. Khademalhosseini, Z., Ahmadi, J., Khademalhosseini, M. Prevalence of Smoking, and its Relationship with Depression, and Anxiety in a Sample of Iranian High School Students. (2015) Enliven Pharmacovigil Drug Saf 1(1): 005.

28. Ahmadi, J., Amiri, A., Ghanizadeh, A., et al. Prevalence of Addiction to the Internet, Computer Games, DVD , and Video and Its Relationship to Anxiety and Depression in a Sample of Iranian High School Students. (2014) Iran J Psychiatry Behav Sci 8(2): 7580.

29. Ahmadi, J., Soltani, F., Tabatabaee, F., et al. Substance Use Disorders in Patients with Lung or Heart Diseases. (2014) Sch J App Med Sci 2(1A): 111120.

30. Ahmadi, J., Yazdanfar, F. Substance use among Iranian university students. (2002) The International Journal of Drug Policy 13(6): 507508 .

31. Ahmadi, J., Sharifi, M. Lifetime and Current Prevalence of Tobacco Smoking. (2013) J Addict Res Ther 4: 145.

32. Ahmadi, J., Ahmed, M.G. Dubai Medical College Students' Attitudes towards Substance Use. (2013) J Addict Res Ther S6: 005.

33. Ahmadi, J., Keshtkar, M., Pridmore, S. Methamphetamine Induced Synesthesia: A Case Report. (2011) Am J Addict 20(3): 306.

34. Ahmadi, J., Naghshvarian, M., Afshari, R. Opioid abuse in male population referred for mandatory Urine Opioid Screen before marriage in ShirazIran. (2011) Iranian J Psychiatry Behav Sci 5(2): 126130.

35. Ahmadi, J., Kampman, K., Osline, D.M., et al. Predictors of Treatment Outcome in Outpatient Cocaine and Alcohol Dependence Treatment. (2009) Am J Addict 18(1): 81-86.

36. Ahmadi, J., Kamel, M., Ahmed, M.G., et al. Dubai Medical College students' scores on the Beck Depression Inventory. (2008) Iranian Red Crescent Journal 10(3): 169172.

37. Ahmadi, J., Benrazavi, L., Babaeebeigi, M., et al. Substance use in a sample of medical patients. (2008) J Psychoactive Drugs 40(3): 315319 .

38. Ahmadi, J., Pridmore, S., Alimi, A., et al. Epidemiology of Opium Use in the General Population. (2007) Am J Drug Alcohol Abuse 33(3): 483-491.

39. Ahmadi, J., Kampman, K., Dackis, C., et al. Cocaine withdrawal symptoms identify Type B cocainedependent patients. (2008) Am J Addict 17(1): 6064

40. Ahmadi, J., Kampman, K., Dackis, C. Outcome predictors in cocaine dependence treatment trials. (2006) Am J Addict 15(6): 434439. 41. Ahmadi, J., Fallahzadeh, H., Salimi, A., et al. Analysis of opium use by students of medical sciences. (2006) J Clin Nurs 15(4): 379386. 42. Ahmadi, J., Menzies, P., Maany, I., et al. Pattern of cocaine and heroin abuse in a sample of Iranian general population. (2005) German J Psychiatry 8(1): 14.

43. Ahmadi, J., Farrashbandi, H., Menzies, P., et al. Prevalence of mood and anxiety disorders in a sample of Iranian outpatient opioid addicts. (2005) German J Psychiatry 8(1): 57.
44. Ahmadi, J., Farrashbandi, H., Majdi, B., et al. Substanceinduced anxiety disorder in opioid dependents. (2005) Addictive Disorders \& Their Treatments 14.

45. Ahmadi, J., Majdi, B., Mahdavi, S., et al. Mood disorders in opioid dependent patients. (2004) J Affect Disord 82(1): 139142.

46. Ahmadi, J., Maharlooy, N., Alishahi, M. Substance abuse: prevalence in a sample of nursing students. (2004) J Clin Nurs 13(1): 6064.

47. Ahmadi, J., Alavi, M., Alishahi, M. Substance Use Disorders in a Sample of Iranian Secondary School Students. (2004) Social Indicators Research 65(3): 355360.

48. Ahmadi, J., Etminan, H., Javanmardi, H. Reasons for cessation of opiate use among Iranian opioids dependants. (2003) Addictive Disorders \& Their Treatment 2(1): 912.

49. Ahmadi, J., Rayisi, T., Alishahi, M. Analysis of substance use by primary school students. (2003) German J Psychiatry 3: 5659.

50. Ahmadi, J., Sharifi, M. Cannabis abuse in Iran. (2003) Irish J Med Sci 172(1): 46

51. Ahmadi, J., Arabi, H., Mansouri, Y. Prevalence of substance use among offspring of opioid addicts. (2003) Addict Behav 28(3): 591595. 52. Ahmadi, J., Hasani, M. Prevalence of substance use among Iranian high school students. (2003) Addict Behav 28(2): 375379.

53. Ahmadi, J., Benrazavi, L. Substance use among Iranian physical patients. (2002) Int J Drug Policy 13(6): 505506.

54. Ahmadi, J., Ostovan, M. Substance use among Iranian male students. (2002) Int J Drug Policy 13(6): 511512.

55. Ahmadi, J., Benrazavi, L. Substance use among Iranian nephrologic patients. (2002) Am J Nephrol 22(1): 1113.

56. Ahmadi, J., Benrazavi, L. Substance use among Iranian surgical patients. (2002) Int J Drug Policy 13(6): 509510.

57. Ahmadi, J., Benrazavi, L. Substance use among Iranian cardiovascular patients. (2002) Eur J Med Res 7(2): 8992.

58. Ahmadi, J., Benrazavi, L., Ghanizadeh, A. Substance abuse among contemporary Iranian medical students and medical patients. (2001) J Nerv Ment Dis 189(12): 860861.

59. Ahmadi, J., Fakoor, A, Pezeshkian, P., et al. Substance use among Iranian psychiatric inpatients. (2001) Psychol Rep 89(2): 363365.

60. Ahmadi, J., Khalili, H., Jooybar, R., et al. Prevalence of cigarette smoking in Iran. (2001) Psychol Rep Oct 89(2): 339341.

61. Ahmadi, J., Ghanizadeh, A. Current substance use among Iranian medical students. (2001) Ind J Psychiat 43(2): 157161.

62. Ahmadi, J., Khalili, H., Jooybar, R., et al. Cigarette smoking among Iranian medical students, resident physicians and attending physicians. (2001) Eur J Med Res 6(9): 406408.

63. Ahmadi, J., Ghanizadeh, A. Motivations for use of opiates among addicts seeking treatment in Shiraz. (2000) Psychol Rep 87(3): 11581164.

64. Ahmadi, J., Toobaee, S., Kharras, M., et al. Psychiatric disorders in opioid dependants. (2003) Int J Soc Psychiatry 49(3): 185191.

65. Ahmadi, J., Pridmore, S., Ekramzadeh, S. Successful Use Of Electro Convulsive Therapy In The Management Of Methamphetamine Induced Psychosis With Onset During Intoxication. (2015) J Addict \& Depend 1(1): 12.

66. Ahmadi, J., Dehghanian, I., Razeghian-Jahromi, L. Poly substance induced psychosis (2015) Sch. J. App. med. Sci 3(7D): 2693-2695.

67. Ahmadi, J., Dehghanian, I., RazeghianJahromi, L. Substance induced disorder. (2015) Sch J App Med Sci 3(7D): 2700-2703.
Ommega Online Publishers

Journal Title: Journal of Addiction and Dependence(JAD)

Journal Short Name: J Addict Depend
ISSN no: 2471-061X

E-mail: addiction.depend@ommegaonline.org Website: www.ommegaonline.org 